\title{
World Journal of Pediatric Surgery \\ Postoperative complications of colectomy and J-pouch with ileostomy versus without ileostomy in children with inflammatory bowel diseases: a systematic review and meta-analysis
}

\author{
Irina Oltean, ${ }^{1}$ Nicole Travis, ${ }^{1}$ Manvinder Kaur, ${ }^{1}$ Viviane Grandpierre, ${ }^{1}$ \\ Lamia Hayawi, ${ }^{2}$ Anne Tsampalieros, ${ }^{2}$ Ahmed Nasr ${ }^{1,3}$
}

To cite: Oltean I, Travis N, Kaur M, et al. Postoperative complications of colectomy and $\mathrm{J}$-pouch with ileostomy versus without ileostomy in children with inflammatory bowel diseases: a systematic review and metaanalysis. World JnI Ped Surgery 2022:5:e000354. doi:10.1136/ wjps-2021-000354

- Additional supplemental material is published online only. To view, please visit the journal online (http://dx.doi.org/10.1136/ wjps-2021-000354).

Received 24 August 2021 Accepted 26 November 2021

D) Check for updates

(C) Author(s) (or their employer(s)) 2022. Re-use permitted under CC BY-NC. No commercial re-use. See rights and permissions. Published by BMJ.

${ }^{1}$ Department of Surgery, Children's Hospital of Eastern Ontario, Ottawa, Ontario, Canada ${ }^{2}$ Children's Hospital of Eastern Ontario Research Institute, Clinical Research Unit, Ottawa, Ontario, Canada

${ }^{3}$ University of Ottawa, Ottawa, Ontario, Canada

Correspondence to DrAhmed Nasr; anasr@cheo. on.ca

\section{ABSTRACT}

Background The efficacy of performing a restorative proctocolectomy and J-pouch ileoanal anastomosis without diverting ileostomy in children with inflammatory bowel disease has been a longstanding debate. A systematic review and meta-analysis is presented comparing the occurrence of postoperative complications in children who underwent either the pouch-anal anastomosis (IPAA) with ileostomy (diverted) versus the undiverted procedure.

Methods Records were sourced from CINAHL, CENTRAL, EMBASE and MEDLINE databases. Studies followed the Preferred Reporting Items for Systematic Reviews and Meta-Analyses guidelines and compared postoperative complications in pediatric patients diagnosed with inflammatory diseases aged less than 18 years who underwent J-pouch with ileostomy versus without ileostomy. The primary outcome was the occurrence of postoperative leaks, and the secondary outcomes were presence of postoperative small bowel obstruction (SB0), pouchitis, stricture and fistula complications. A randomeffects meta-analysis was used.

Results Twenty-three observational studies in the systematic review were included with 658 patients $(83 \%$ diverted, $17 \%$ undiverted). Pooled estimates showed no difference in occurrence of leaks in children who underwent J-pouch/IPAA with ileostomy versus without (odds ratio (OR) $0.54,95 \%$ confidence interval (Cl) 0.17 to $1.64, I^{2}=16 \%$ ). There was no difference in the occurrence of SBO, pouchitis or strictures in children who underwent J-pouch/IPAA with ileostomy versus without (SB0: OR 2.27, $95 \% \mathrm{Cl} 0.52$ to $9.92, \mathrm{I}^{2}=0 \%$, pouchitis: OR $1.76,95 \% \mathrm{Cl}$ 0.95 to $3.24, I^{2}=0 \%$, strictures: $0 R 2.72,95 \% \mathrm{Cl} 0.44$ to $16.69, I^{2}=66 \%$ ).

Conclusion The meta-analysis did not find differences in the occurrence of complications in pediatric patients who underwent the IPAA with ileostomy procedure versus without ileostomy.

\section{INTRODUCTION}

Inflammatory bowel disease (IBD) refers to a group of chronic, relapsing autoimmune diseases that result in chronic intestinal inflammation of both the small and large intestine. Affecting 1.5 million North Americans, the cause of this disease is not yet known but is proposed to occur as a result of inappropriate immune response to environmental factors as well as luminal and microbial antigens. ${ }^{12}$ Although the onset of this disease typically manifests during adulthood, children are increasingly being diagnosed with IBD. ${ }^{3}$

Since 1978, the gold standard surgical treatment of ulcerative colitis (UC) is restorative proctocolectomy with ileal pouch-anal anastomosis (RP-IPAA), which can be performed via laparoscopic or open procedure, in one, two or three stages and constructed with an S-reservoir, a J-reservoir or a W-reservoir. ${ }^{4}$ Data from Widmar et a $\bar{l}^{\bar{p}}$ suggest that diversion does not prevent pouch excision and a need for long-term diversion after pouch leak in adult patients. Recently, Khalid et at demonstrated greater probability of anastomotic strictures (odd ratio (OR) $0.40 ; 95 \%$ confidence interval (CI) 0.26 to $0.62, \mathrm{p}<0.0001$ ) and pouch failures (OR 0.54 (0.36 to 0.82 ), $\mathrm{p}=0.003$ ) in adult diverted than in non-diverted patients, although reoperation was more frequently required in non-diverted patients (OR 2.51 (1.12 to 5.59), $\mathrm{p}=0.02)$. Hence, results are still inconclusive, debatable and rarely focus on pediatric populations with consideration of numerous postoperative complications.

Systematic reviews investigating certain postoperative complications in children who undergo diverting ileostomy procedures versus not are lacking. Moreover, differences in short-term and long-term outcomes for pediatric patients who undergo IPAA are limited owing to constraints in study design 
and infrequency of IPAA in children. To address this gap, an investigation is needed comparing the frequency of postoperative complications between diverted versus undiverted IPAA procedures in a pediatric population aged less than 18 years diagnosed with IBD.

The objective of this systematic review and metaanalysis was to compare the frequency of postoperative complications in pediatric patients with IBD who have done IPAA with ileostomy (diverted) versus without ileostomy (undiverted). Secondary objectives included estimating the pooled frequency of these complications in the surgical groups.

\section{METHODS}

This review followed the Cochrane Methodology to identify and select the studies ${ }^{7}$ and the Preferred Reporting Items for Systematic Reviews and Meta-Analyses to guide the reporting of this systematic review. ${ }^{8}$

\section{Search strategy and selection criteria}

A systematic search for relevant studies published between 1946 and November 4, 2019 was performed using the following databases: CINAHL (1982 onwards), CENTRAL, EMBASE (1980 onwards) and MEDLINE (1996 onwards). Twenty-two studies were included after this initial search. An update was performed in July 2021 identifying three additional eligible studies. ${ }^{9-11}$ Searches were developed and conducted by a librarian experienced in systematic reviews, using a method designed to optimize term selection, ${ }^{12}$ and the MEDLINE search was peer reviewed by a second librarian before being translated for the other databases. Search strategies are presented in the online supplemental file 1 . The study protocol has been registered in Open Science Framework (10.31219/osf.io/svuwm). All duplicate records were removed online, records retrieved by the electronic search were downloaded and imported into a Reference Manager - a citation database, and then were uploaded to a systematic review software Covidence (www.covidence.org) for title and abstract screening and full-text review. Four reviewers (IO, MK, NT, VG) screened at title/abstract level and full-text review stages. Citations were excluded if at least two reviewers agreed to exclude. Disagreements were reviewed and were resolved by the study leads, where necessary (AN). The study co-lead (IO) reviewed all eligible citations to confirm eligibility.

\section{Inclusion criteria}

Randomized controlled trials, cohort and case-control studies examining the postoperative complications in pediatric patients diagnosed with inflammatory diseases (ie, ulcerative colitis, indeterminate colitis or unclassified IBD) aged less than 18 years who underwent J-pouch with ileostomy or without ileostomy were included. This age limit was chosen to reflect consistency with published literature on children in the field. ${ }^{13-15}$

\section{Exclusion criteria}

Studies were excluded if documented complications were not provided for the surgery performed or did not mention the primary endpoints of interest. Case studies, literature reviews, systematic reviews, editorials, letters to the editor, conference abstracts and commentaries were excluded, in addition to studies not written in English.

\section{Data extraction and outcomes}

Two authors (IO and NT) extracted patient frequencies using a predesigned and piloted data abstraction sheet in Excel V.14.7.7. The extracted information included study details (design, location of the study and sample size), patient demographics including age and gender, disease diagnosis, average or median follow-up, and surgical details including the procedure implemented.

The primary clinical outcome was the occurrence of anastomosis leaks. The secondary outcomes included the occurrence of small bowel obstruction, pouchitis, strictures and fistula (duodenal, enterovaginal or rectovaginal) at the designated follow-up period, as defined by the study author.

A diagnosis of stricture at the anastomosis was confirmed on examination and/or endoscopy, and anastomotic leak was defined as evidence of leak on imaging (such as pelvic fluid collection adjacent to the anastomosis) or at reoperation. Small bowel obstruction was defined by a contrast-enhanced X-ray or a CT result, demonstrating findings for obstruction, in tandem with abdominal pain, vomiting, abdominal distention, nausea, and/or decreased or absent flatus and/or stool. Late obstruction was defined as occurring after closure of the covering ileostomy. Rectovaginal fistula could have been detected on MRI, after restorative proctocolectomy. Pouchitis was primarily diagnosed clinically by symptoms of increased stool frequency, abdominal pain, and fecal incontinence and endoscopically confirmed, and was defined as inflammation in the pouch in a symptomatic patient who may have been prescribed antibiotics in the year prior to follow-up.

\section{Assessment of risk of bias within studies}

Two reviewers (NT and IO) independently reviewed each study. The validated Methodological Index for Non-Randomized Studies (MINORS) criteria were used to assess the quality of the studies. ${ }^{16}$ Items assessed included clearly stated aims, inclusion and representativeness of patients, reliable prospective data collection, appropriate and unbiased endpoints, sufficient follow-up period, follow-up loss, adequate study size calculation, contemporary groups (to address historical bias), baseline equivalence and adequate statistical analysis. ${ }^{16}$ Items 1 through 7 apply to non-comparative, while items 8 though 12 for comparative studies. Records were given scores of 0 through 2 for 12 criteria of bias assessment. The maximum (ideal) global score is 24 for comparative studies and is 16 for non-comparative studies. 


\section{Statistical analysis}

All statistical analyses were performed using the R statistical programming language (V.4.0.3). ${ }^{17}$ Continuous valued variables were expressed as mean $\pm \mathrm{SD}$, and categorical variables were expressed as numbers and percentages. Inter-rater reliability was assessed between reviewers in assessing quality of the studies using weighted kappa for each of the 12 items of the MINORS scale and using a two-way model, single rater intraclass correlation coefficients (ICCs) or the total MINORS score. ${ }^{18}$ Data were meta-analyzed using a random-effects model with $\mathrm{R}$ package 'meta'. ${ }^{19}$ Pooled ORs were generated using Mantel-Haenszel test, using a random-effects model. If there were not enough studies (a minimum of two studies) to compare the two types of surgery, the proportion was pooled with a $95 \%$ CI for the complication for one type of surgical procedure using random effects. Statistical heterogeneity was determined using $\mathrm{I}^{2}$ tests. $\mathrm{I}^{2}$ is the proportion of total variation observed between studies attributable to differences between studies rather than sampling errors. High heterogeneity was defined as $\mathrm{I}^{2}>75 \%$.

\section{RESULTS}

\section{Study selection}

The initial search yielded 1080 studies of which 22 were originally included after full-text review. Two records were found to have patient overlap and thus were removed from the review before performing the update. ${ }^{2021}$ After an update was performed, there were 23 total studies that met the inclusion criteria and were included in the systematic review. Seven of these studies were used in the meta-analysis $^{91122-26}$ (figure 1).

\section{Study characteristics and individual results}

Characteristics of the 23 studies with 658 patients can be found in online supplemental file 2, table S1. A total of $547(83 \%)$ and $111(17 \%)$ underwent IPAA with ileostomy or IPAA without ileostomy, respectively.

Of the 23 studies, the mean age of patients who underwent surgery ranged between 10.4 and 16.3 years. Based on the definition of IBD inclusion in each study, 714 (714 of $719,99 \%$ ) children presented with only clinically diagnosed UC (diagnosed via preoperative biopsies, histologic examinations of surgical specimens, endoscopy or a combined approach) or indeterminate colitis ( 5 of 719, $1 \%$ ) diagnosed with indeterminate colitis discerned from a combination of standard laboratory tests, fecal markers of inflammation, serological biomarkers and gastrointestinal endoscopy with biopsies. ${ }^{21}$

There was wide variability in the percentage of females included (25\%-90\%). Across all studies, follow-up was at least 1 year. Of the 23 studies, 7 (32\%) described conducting IPAA with ileostomy in one or two stages, ${ }^{20-22 ~ 27-30} 8(35 \%)$ in three stages, ${ }^{1031-37}$ and $2(9 \%)$ in one, two or three stages. ${ }^{2638}$ The remaining six (26\%) were not well defined. ${ }^{23-25} 39-41$

Of the seven studies quantifying our outcomes in the groups of IPAA with ileostomy versus without, ${ }^{91122-26}$ four $(67 \%)$ reported no significant differences in preoperative characteristics among their cohorts. ${ }^{22-25}$ Four $(67 \%)$ stratified baseline characteristics, such as age, sex, duration of

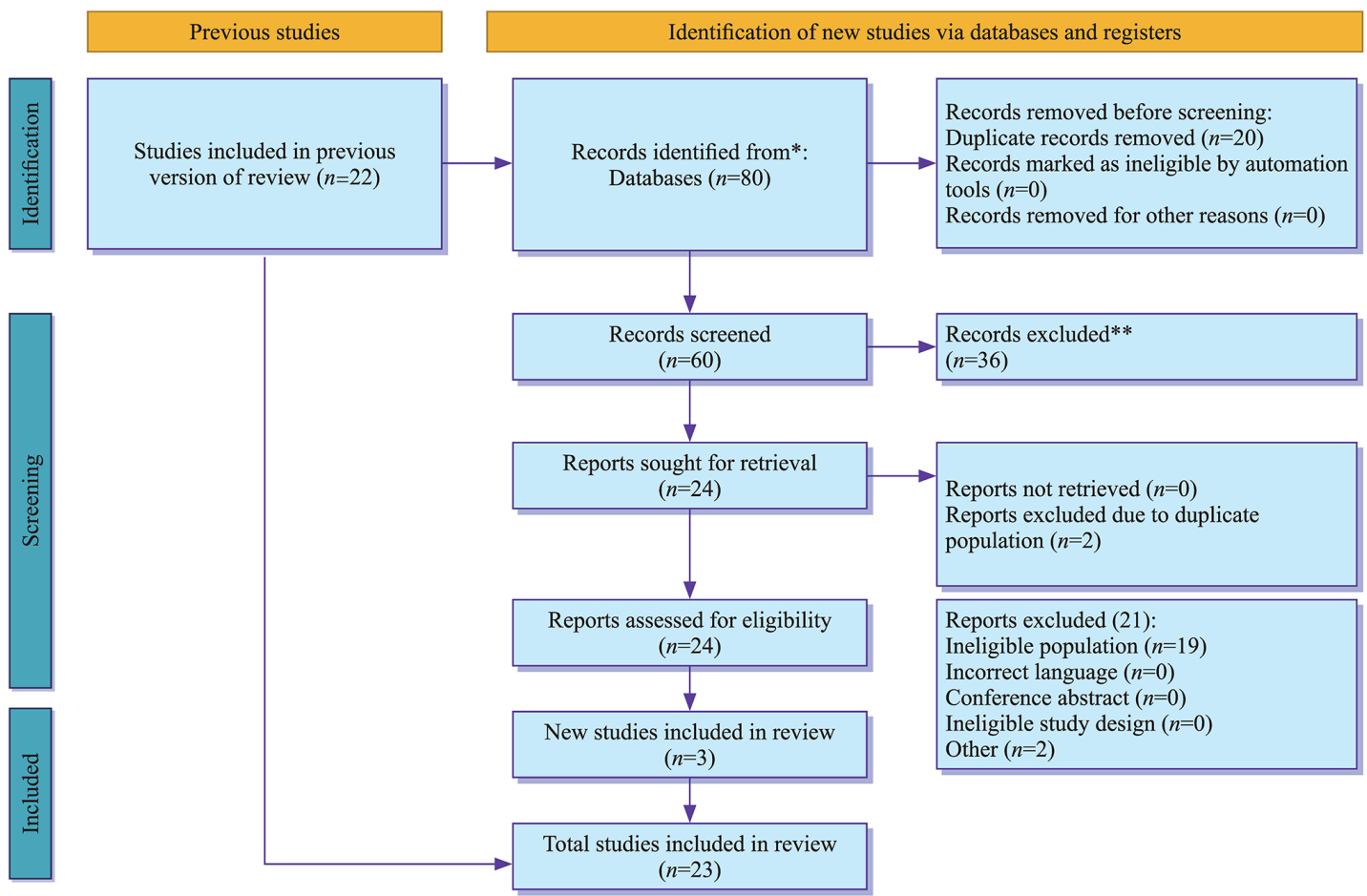

Figure 1 Preferred Reporting Items for Systematic Reviews and Meta-Analyses 2020 flow diagram for updated systematic reviews which included searches of databases and registers only. 


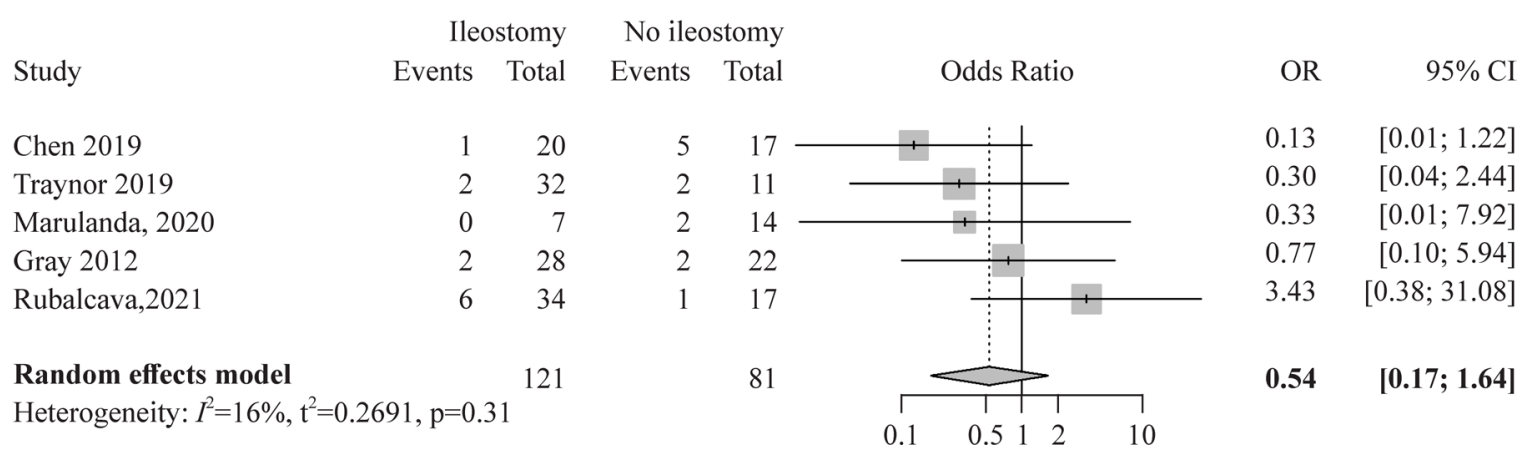

Figure 2 Meta-analysis forest plot for leaks in diverted vs undiverted ileostomy groups.

illness before resection or immunosuppression at time of surgery. ${ }^{22-25}$ Indications for surgery included chronic anal pain and failure to achieve full continence (one study $(17 \%))^{22}$ and acute presentation of UC refractory to medical intervention (one $(17 \%)) .{ }^{20}$ One study $(17 \%)$ included an urgent case in their cohort. ${ }^{22}$

\section{Risk of bias across studies}

Moderate agreement was achieved across the 12 items of the MINORS scale (weighted kappa 0.66, 95\% CI 0.57 to 0.75 and when examining the total score for all included studies (ICC $0.68,(0.37$ to 0.85$)$ ). MINORS scores for comparative studies $(\mathrm{n}=17)$ ranged from 17 to 20 , with mean 17.4 \pm 1.5 . MINORS scores for non-comparative studies $(n=6)$ ranged from 8 to 12 , with a mean of $10.1 \pm 1.5$. The ideal global score is 16 for non-comparative studies and is 24 for comparative studies, which indicates fair study quality based on this definition ${ }^{16}$ Please see online supplemental file 3 for the methodological appraisal of observational studies (online supplemental table S2).

\section{Primary analysis outcome}

\section{Leaks}

There were five comparative studies that reported on leaks. ${ }^{911232526}$ The pooled estimate showed no difference in postoperative risk of leaks among patients who underwent the J-pouch with ileostomy procedure as compared with patients with J-pouch without ileostomy (OR 0.54, $95 \%$ CI 0.17 to $1.64, \mathrm{I}^{2}=16 \%$ ) (figure 2 ).

\section{Secondary analysis outcomes}

\section{Small bowel obstruction}

Three studies were included in the pooled meta-analysis for the complication of small bowel obstruction. ${ }^{9} 2325$ The pooled estimate indicated no difference in the odds of small bowel obstruction in children with ileostomy versus without (OR 2.27, 95\% CI 0.52 to $9.92, \mathrm{I}^{2}=0 \%$ ) (figure 3A).

\section{Pouchitis}

There were six relevant studies included in the pooled meta-analysis, ${ }^{9} 11$ 22-25 the pooled estimate suggested no difference in patients with J-pouch and ileostomy developing pouchitis compared with patients without ileostomy (OR $1.76,95 \%$ CI 0.951 to $3.24, \mathrm{I}^{2}=0 \%$ ) (figure $3 \mathrm{~B}$ ).

\section{Strictures}

There were two studies that reported on strictures in J-pouch with ileostomy versus without. The pooled estimate showed no difference in risk of strictures between patients with J-pouch with ileostomy versus without (OR 2.72; $95 \%$ CI 0.44 to $16.69, \mathrm{I}^{2}=66 \%$ ) (figure $3 \mathrm{C}$ ).

\section{Fistula}

None of the included studies compared the occurrence of fistula between the two surgery types; nor was fistula reported across the studies for pediatric patients without ileostomy. Therefore, the proportion of fistula complication was pooled only in pediatric patients who underwent J-pouch with ileostomy. ${ }^{10} 30323438$ Pooled prevalence of fistula in these patients was $2.0 \%$ (95\% CI $0.0 \%$ to $4.0 \%$, $\mathrm{I}^{2}=0 \%$ ) (figure 4).

\section{DISCUSSION}

This systematic review included 23 studies (658 patients), among which 7 studies quantified complications of interest between the J-pouch/IPAA with ileostomy procedure versus without. Results from the meta-analysis demonstrated that there is no difference in postoperative complications, specifically anastomotic leaks, when comparing pediatric patients with J-pouch with ileostomy versus patients with J-pouch without ileostomy. Avoiding a diverting ileostomy in select patients could be a safe alternative because there is no evidence of a protective benefit against leaks when using a diverting ileostomy. The majority of studies had small sample sizes, with CIs overlapping one, which reduces statistical confidence in the findings. In the adult literature, anastomotic leak rates range from $5 \%$ to $19 \%,{ }^{42-44}$ and there seems to be a trend towards decreased clinically detectable leak rates in the diverted versus undiverted group. ${ }^{23}$ This finding does not align with previous literature reporting higher incidence of anastomotic leakage in the undiverted than diverted populations. ${ }^{42} 45-48$

No statistical difference was found in small bowel obstruction in diverted versus undiverted pediatric patients, which contrasts with prior literature. Although the target populations differ, one study of a clinical sample of adults showed significantly higher odds of small bowel obstruction in diverted patients (OR 5.05 (1.35 to 18.92)) 

(1)

A) Small bowel obstruction

A) Small bowel obstruction
Gray 2012
Chen 2019
Rubalcava, 2021
Marulanda, 2020

Random effects model

$\begin{array}{rrrr}2 & 28 & 1 & 22 \\ 1 & 20 & 0 & 17 \\ 5 & 34 & 1 & 17 \\ 0 & 7 & 0 & 14 \\ & \mathbf{8 9} & & \mathbf{7 0}\end{array}$

Heterogeneity: $I^{2}=0 \%, \mathrm{t}^{2}=0, \mathrm{p}=0.95$

B) Pouchitis

Chen 2019

BismarB 2019

Rubalcava, 2021

Gray 2012

Marulanda, 2020

Dolgin 1999

Random effects model

Heterogeneity: $I^{2}=0 \%, \mathrm{t}^{2}=0, \mathrm{p}=0.70$

$\begin{array}{rrrr}9 & 20 & 7 & 17 \\ 9 & 27 & 4 & 14 \\ 26 & 34 & 11 & 17 \\ 11 & 28 & 6 & 22 \\ 1 & 7 & 0 & 14 \\ 5 & 14 & 1 & 16 \\ & \mathbf{1 3 0} & & \mathbf{1 0 0}\end{array}$

22
17
17
14
70

Odds Ratio

OR $\quad 95 \% \mathrm{CI}$

C) Stricture

BismarB 2019

Rubalcava, 2021

Random effects model

Heterogeneity: $I^{2}=66 \%, \mathrm{t}^{2}=1.1300, \mathrm{p}=0.09$

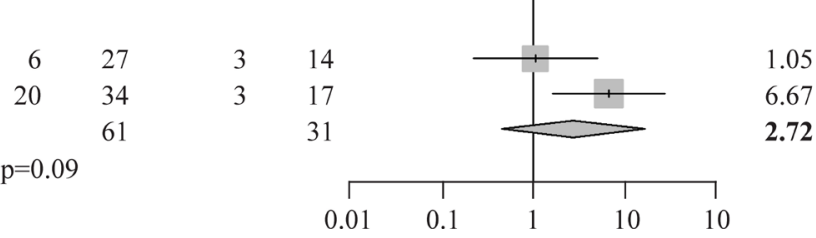

$\begin{array}{ll}1.62 & {[0.14 ; 19.07]} \\ 2.69 & {[0.10 ; 70.49]} \\ 2.76 & {[0.30 ; 25.71]} \\ \mathbf{2 . 2 7} & {[\mathbf{0 . 5 2} ; \mathbf{9 . 9 2}]}\end{array}$

$1.17 \quad[0.32 ; 4.32]$

$1.25 \quad[0.31 ; 5.11]$

$1.77 \quad[0.50 ; 6.32]$

$1.73 \quad[0.52 ; 5.77]$

$6.69 \quad[0.24 ; 187.28]$

$8.33 \quad[0.84 ; 83.17]$

$1.76 \quad[0.95 ; 3.24]$

$1.05 \quad[0.22 ; 5.02]$

$6.67 \quad[1.61 ; 27.63]$

$2.72 \quad[0.44 ; 16.69]$

Figure 3 (A) Meta-analysis forest plot for secondary outcome complications in diverted vs undiverted ileostomy groups for small bowel obstruction. (B) Meta-analysis forest plot for secondary outcome complications in diverted vs undiverted ileostomy groups for pouchitis. (C) Meta-analysis forest plot for secondary outcome complications in diverted vs undiverted ileostomy groups for stricture.

than undiverted patients after adjusting for steroid use, age, length of follow-up, prior subtotal colectomy and primary preoperative diagnosis. ${ }^{49-53}$ Moreover, restorative proctocolectomy requires extensive bowel manipulation and pelvis dissection, and manipulating the small bowel for ileostomy might increase the incidence of clinically distinguished small bowel obstruction. ${ }^{53-57}$ Additionally, small bowel obstruction resulting from an abscess is a prevalent complication after proctocolectomy and ileoanal anastomosis. ${ }^{58}$

The meta-analysis did not find evidence of increased odds of pouchitis in children who underwent J-pouch/ IPAA with ileostomy versus without ileostomy, given that the CIs overlapped one due to small sample sizes. This finding suggests non-inferiority of the diverting ileostomy approach. Larger sample size studies are warranted. Pouchitis is the most prevalent long-term complication in patients who undergo IPAA. Sixty per cent of affected children suffer from recurrent episodes and $5 \%-10 \%$ can develop chronic pouchitis. ${ }^{59} 60$ Pouchitis can develop in $80 \%$ of adult patients after RP-IPAA, significantly impairing quality of life. ${ }^{61}{ }^{62}$ Literature suggests similar pouchitis rates between diverted versus undiverted groups, likely due to comparable operative techniques for building the IPAA. In fact, Dolgin $e t a l^{24}$ reported no significant difference between the J-pouch and ileostomy versus without ileostomy procedures, in terms of complications or functional outcomes and no patient developed a significant pouch complication in either group. Hence, the diverting stoma did not affect pouchitis occurrence, ${ }^{22}$ although one study suggests that creating a diverting ileostomy could avoid consequences of pouch leak or failure by enabling recovery of anal sphincter function. ${ }^{45}$ Pouchitis may occur more frequently in IPAA with

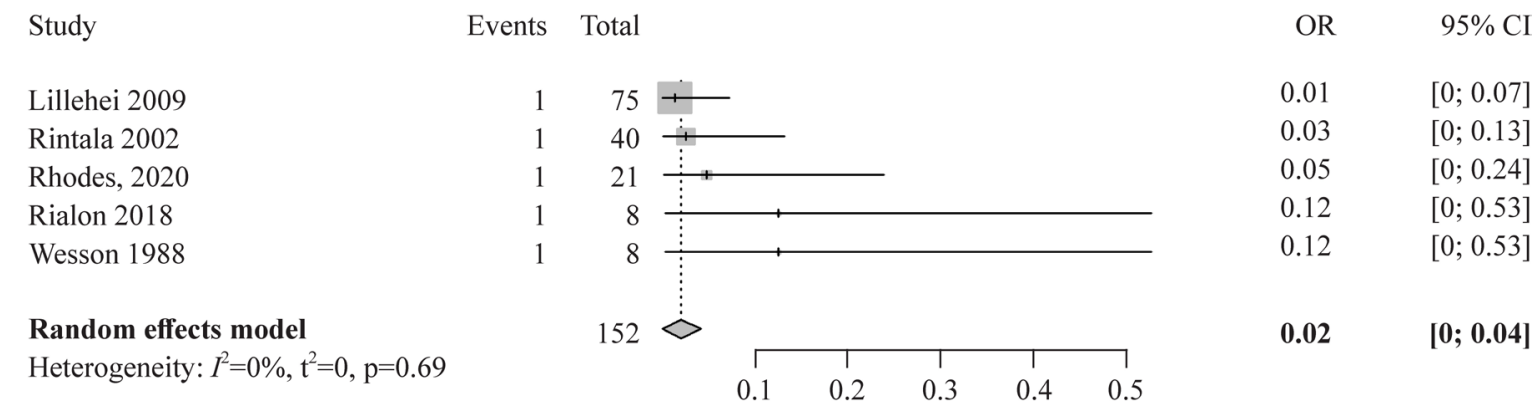

Figure 4 Forest plot for the proportion of fistula complication in patients with J-pouch with ileostomy. 
ileostomy patients owing to inflammatory stasis within the reservoir, particularly from larger reservoirs, which empty only partially during defecation. ${ }^{63}$

Among the two studies reporting strictures, the pooled estimate showed no difference in risk of strictures between patients with J-pouch with ileostomy versus without. ${ }^{9} 22$ Similarly, previous literature reports comparable frequencies in anastomotic strictures between undiverted versus diverted groups because pouch anastomosis leaks can resolve without significantly contributing to symptoms, resulting from dilatation treatment. Despite this, Gawad $e t a l^{64}$ and other authors propose that residual, active disease at the ileoanal anastomosis site could still compromise healing, and the extent of inflammation in resected surgical specimens predicts pouchrelated complications, such as anastomotic stricture and leaks post-IPAA. ${ }^{2065}$

In this review, the percentage of fistula in pediatric patients who underwent J-pouch with ileostomy was low (at 2\%). This aligns with previous literature indicating low prevalence of fistula in children with familial adenomatous polyposis (FAP) and UC postoperation for J-pouch. ${ }^{667}$

\section{Limitations}

Overall, the biggest limitations include: (1) lack of consistent outcome reporting; (2) lack of studies comparing the two surgical approaches for pooled analysis and (3) lack of data on other confounding risk factors (including age, body mass index (BMI), case urgency, nutritional status, etc). Addressing each of these concerns would enable direct comparison between the defined outcomes based on clinical factors. Second, the estimates collected in this systematic review are based on observational studies and not on randomized controlled trials. However, randomizing by surgery type is a difficult approach, and only one study has randomized by diversion. ${ }^{68}$ Lastly, surgeons may have a clinical preference towards undiverted surgery in patients who are 'healthier' (ie, lack of anastomosis tension, good pelvic dissection, nutritional status and decreased immunosuppressant doses) ${ }^{5}$ because an undiverted pouch can have more favorable preoperative and operative characteristics and because diversion does not always prevent pouch excision. ${ }^{525670}$ This potential preference might explain why there were so few studies comparing the outcomes directly between IPAA diverted versus undiverted ileostomy procedures.

In conclusion, this meta-analysis suggests no difference in the number of anastomotic leaks, or in small bowel obstruction, pouchitis and stricture in IPAA with ileostomy versus no ileostomy. Future studies are encouraged to report short-term and long-term outcomes consistently for pouch surgery so that pooled analyses can be performed. In particular, a future investigation of leaks, strictures, long-term function, acute and chronic pouchitis, and level of intervention to control these complications, including antibiotics, immunotherapy or pouch excision, is warranted. If sample size permits, studies are encouraged to stratify their outcomes by diversion status as well as IBD type to identify specific differences in complications among children. Because the presence of intestinal occlusions could be highly correlated in IPAA with ileostomy from adhesions, ${ }^{54} 71$ capturing adhesions data in a subsequent review is recommended. Finally, standard preoperative health criteria for choosing undiverted or diverted procedures should be developed to optimize surgery selection for children with IBDs.

Acknowledgements Margaret Sampson (Children's Hospital of Eastern Ontario) can be thanked for developing the electronic search strategies and Lindsey Sikora (University of Ottawa) for peer review of the MEDLINE search strategy.

Contributors 10 contributed to data curation, investigation, methodology, project administration, visualization, validation, writing (original draft) and writing (review and editing). NT contributed to investigation, validation and writing (review and editing). MK contributed to validation, visualization and writing (review and editing). VG contributed to validation and visualization. LH contributed to formal analysis, methodology, software, supervision, validation, visualization and writing (review and editing). AT contributed to formal analysis, methodology, software, supervision, validation, visualization and writing (review and editing). AN contributed to conceptualization, investigation, methodology, project administration, supervision, validation and writing (review and editing).

Funding The authors have not declared a specific grant for this research from any funding agency in the public, commercial or not-for-profit sectors.

Competing interests None declared.

Patient consent for publication Not required.

Ethics approval This study does not involve human participants.

Provenance and peer review Not commissioned; externally peer reviewed.

Data availability statement Data are available upon reasonable request. Data are available on reasonable request.

Open access This is an open access article distributed in accordance with the Creative Commons Attribution Non Commercial (CC BY-NC 4.0) license, which permits others to distribute, remix, adapt, build upon this work non-commercially, and license their derivative works on different terms, provided the original work is properly cited, appropriate credit is given, any changes made indicated, and the use is non-commercial. See: http://creativecommons.org/licenses/by-nc/4.0/.

\section{REFERENCES}

1 Jairath V, Feagan BG. Global burden of inflammatory bowel disease. Lancet Gastroenterol Hepatol 2020;5:2-3.

2 de Souza HSP, Fiocchi C. Immunopathogenesis of IBD: current state of the art. Nat Rev Gastroenterol Hepatol 2016;13:13-27.

3 Fakhoury M, Negrulj R, Mooranian A, et al. Inflammatory bowel disease: clinical aspects and treatments. $J$ Inflamm Res 2014; 7:113-20.

4 Sofo L, Caprino P, Sacchetti F, et al. Restorative proctocolectomy with ileal pouch-anal anastomosis for ulcerative colitis: a narrative review. World J Gastrointest Surg 2016;8:556.

5 Widmar M, Munger JA, Mui A, et al. Diverted versus undiverted restorative proctocolectomy for chronic ulcerative colitis: an analysis of long-term outcomes after pouch leak short title: outcomes after pouch leak. Int J Colorectal Dis 2019;34:691-7.

6 Khalid K, Manzoor T, Khan S. Is diversion free ileal pouch-anal anastomosis a safe procedure? A meta-analysis of 4973 cases. Int $J$ Colorectal Dis 2021;36:1-15.

7 Higgins J, Thomas J, Chandler J, et al. Cochrane Handbook for systematic reviews of interventions. Second ed. The Cochrane collection, 2019. https://onlinelibrary.wiley.com/doi/book/10.1002/ 9781119536604

8 Page MJ, McKenzie JE, Bossuyt PM, et al. The PRISMA 2020 statement: an updated guideline for reporting systematic reviews. Syst Rev 2021;10:1-10.

9 Rubalcava NS, Moreno NA, Adler J, et al. Does the timing of pouch creation in 2-stage operations for pediatric patients with ulcerative colitis matter? J Pediatr Surg 2021;56:1203-7. 
10 Rhodes HL, Cusick E. Single-Center review of staged restorative proctectomy for ulcerative colitis. J Pediatr Surg 2020;55:278-81.

11 Marulanda K, Purcell LN, Egberg MD, et al. Analysis of a modified two-stage approach to ileal pouch-anal anastomosis without fecal diversion in pediatric patients. Am Surg 2022;88:103-8.

12 Bramer WM, de Jonge GB, Rethlefsen ML, et al. A systematic approach to searching: an efficient and complete method to develop literature searches. J Med Libr Assoc 2018;106:531-41.

13 Orkin BA, Telander RL, Wolff BG, et al. The surgical management of children with ulcerative colitis. The old vs. the new. Dis Colon Rectum 1990;33:947-55.

14 Romanos J, Stebbing JF, Mortensen NJ, et al. Restorative proctocolectomy in children and adolescents. J Pediatr Surg 1996;31:1655-8.

15 Odigwe L, Sherman PM, Filler R, et al. Straight ileoanal anastomosis and ileal pouch-anal anastomosis in the surgical management of idiopathic ulcerative colitis and familial polyposis coli in children: follow-up and comparative analysis. J Pediatr Gastroenterol Nutr 1987;6:426-9.

16 Slim K, Nini E, Forestier D, et al. Methodological index for nonrandomized studies (minors): development and validation of a new instrument. ANZ J Surg 2003;73:712-6.

$17 \mathrm{R}$ Core Team. A language and environment for statistical computing, 2021. Available: https://www.r-project.org/ [Accessed 3 Jan 2021].

18 Hallgren KA. Computing inter-rater reliability for observational data: an overview and tutorial. Tutor Quant Methods Psychol 2012;8:23-34.

19 Balduzzi S, Rücker G, Schwarzer G. How to perform a meta-analysis with R: a practical tutorial. Evid Based Ment Health 2019;22:153-60.

20 Bismar N, Patel AS, Schindel DT. Does age affect surgical outcomes after ileal pouch-anal anastomosis in children? J Surg Res 2019;237:61-6.

21 Mattioli G, Pini-Prato A, Barabino A, et al. Laparoscopic approach for children with inflammatory bowel diseases. Pediatr Surg Int 2011;27:839-46.

22 Bismar N, Knod JL, Patel AS, et al. Outcomes following two-stage surgical approaches in the treatment of pediatric ulcerative colitis. $J$ Pediatr Surg 2019;54:1601-3.

23 Chen YJ, Grant R, Lindholm E, et al. Is fecal diversion necessary during ileal pouch creation after initial subtotal colectomy in pediatric ulcerative colitis? Pediatr Surg Int 2019;35:443-8.

24 Dolgin SE, Shlasko E, Gorfine S, et al. Restorative proctocolectomy in children with ulcerative colitis utilizing rectal mucosectomy with or without diverting ileostomy. J Pediatr Surg 1999;34:837-40.

25 Gray BW, Drongowski RA, Hirschl RB, et al. Restorative proctocolectomy without diverting ileostomy in children with ulcerative colitis. J Pediatr Surg 2012;47:204-8.

26 Traynor MD, McKenna NP, Potter DD, et al. The effect of diversion on readmission following ileal pouch-anal anastomosis in children. $J$ Pediatr Surg 2020;55:549-53.

27 Barrena S, Martínez L, Hernandez F, et al. Surgical treatment of chronic inflammatory bowel disease in children. Pediatr Surg Int 2011;27:385-90.

28 Huntington JT, Boomer LA, Pepper VK, et al. Minimally invasive ileal pouch-anal anastomosis with rectal eversion allows for equivalent outcomes in continence in pediatric patients. $J$ Laparoendosc $A d v$ Surg Tech A 2016;26:222-5.

29 Mattioli G, Guida E, Pini-Prato A, et al. Technical considerations in children undergoing laparoscopic ileal-J-pouch anorectal anastomosis for ulcerative colitis. Pediatr Surg Int 2012;28:351-6.

30 Rintala RJ, Lindahl HG. Proctocolectomy and J-pouch ileo-anal anastomosis in children. J Pediatr Surg 2002;37:66-70.

31 Lawal TA, Falcone RA, von Allmen D, et al. The utility of routine pouchogram before ileostomy reversal in children and adolescents following ileal pouch anal anastomosis. J Pediatr Surg 2011;46:1222-5.

32 Lillehei CW, Leichtner A, Bousvaros A, et al. Restorative proctocolectomy and ileal pouch-anal anastomosis in children. Dis Colon Rectum 2009;52:1645-9.

33 Pellino G, Sciaudone G, Miele E, et al. Functional outcomes and quality of life after restorative proctocolectomy in paediatric patients: a case-control study. Gastroenterol Res Pract 2014;2014:1-6.

34 Rialon KL, Crowley E, Seemann NM, et al. Long-Term outcomes for children with very early-onset colitis: implications for surgical management. J Pediatr Surg 2018;53:964-7.

35 Rinawi F, Assa A, Eliakim R, et al. Predictors of pouchitis after ileal pouch-anal anastomosis in pediatric-onset ulcerative colitis. Eur $J$ Gastroenterol Hepatol 2017;29:1079-85.

36 Sarigol S, Wyllie R, Kay M, et al. Ileal pouch-anal anastomosis in children with ulcerative colitis: long-term follow-up. J Pediatr Gastroenterol Nutr 1998:27:472.
37 Motta JC, Ricketts RR. The J-pouch Swenson procedure for ulcerative colitis and familial polyposis. Am Surg 1992;58:613-7.

38 Wesson DE. Early results with the J-pouch procedure in children. Can J Surg 1988;31:182-4.

39 Chew SSB, Kerdic RI, Yang J-L, et al. Functional outcome and quality of life after ileal pouch-anal anastomosis in children and adults. ANZ J Surg 2003;73:983-7.

40 Saklani AP, Marsden N, Davies M, et al. Outcome after restorative proctocolectomy in children and adolescents. Color Dis 2011;13:1148-52.

41 Teitelbaum DH, Lelli JL, Hirschl RB, et al. Laparoscopy-Assisted proctocolectomy for ulcerative colitis: a more rational approach. Pediatric Endosurgery Innov Tech 2001;5:229-33.

42 Zittan E, Ma GW, Wong-Chong N, et al. Ileal pouch-anal anastomosis for ulcerative colitis: a Canadian institution's experience. Int J Colorectal Dis 2017;32:281-5.

43 Zittan E, Wong-Chong N, Ma GW, et al. Modified two-stage ileal pouch-anal anastomosis results in lower rate of anastomotic leak compared with traditional two-stage surgery for ulcerative colitis. $J$ Crohns Colitis 2016;10:766-72.

44 Zerhouni S, Kirsch R, Bakonyi A, et al. Severity of inflammation as a risk factor for ileo-anal anastomotic leak after a pouch procedure in ulcerative colitis. Int J Colorectal Dis 2015;30:1375-80.

45 Weston-Petrides GK, Lovegrove RE, Tilney HS, et al. Comparison of outcomes after restorative proctocolectomy with or without defunctioning ileostomy. Arch Surg 2008;143:406-12.

46 Tjandra JJ, Fazio VW, Church JM, et al. Similar functional results after restorative proctocolectomy in patients with familial adenomatous polyposis and mucosal ulcerative colitis. Am J Surg 1993;165:322-5.

47 Cohen Z, McLeod RS, Stephen W, et al. Continuing evolution of the pelvic pouch procedure. Ann Surg 1992;216:506-12.

48 Ellebaek MB, Dilling Kjaer M, Spanggaard K, et al. Protective loopileostomy in ileal pouch-anal anastomosis for ulcerative colitis advantages and disadvantages. A retrospective study. Colorectal Dis 2021;23:145-52.

49 Sugerman HJ, Sugerman EL, Meador JG, et al. lleal pouch anal anastomosis without ileal diversion. Ann Surg 2000;232:530-41.

50 Heald RJ, Allen DR. Stapled ileo-anal anastomosis: a technique to avoid mucosal proctectomy in the ileal pouch operation. Br J Surg 1986;73:571-2.

51 Tuckson W, Lavery I, Fazio V, et al. Manometric and functional comparison of ileal pouch anal anastomosis with and without anal manipulation. Am J Surg 1991;161:90-6.

52 Wexner SD, James K, Jagelman DG. The double-stapled ileal reservoir and ileoanal anastomosis. Dis Colon Rectum 1991;34:487-94.

53 Stey AM, Brook RH, Keeler E, et al. Outcomes and cost of diverted versus undiverted restorative proctocolectomy. J Gastrointest Surg 2014; 18:995-1002.

54 MacLean AR, Cohen Z, MacRae HM, et al. Risk of small bowel obstruction after the ileal pouch-anal anastomosis. Ann Surg 2002;235:200-6.

55 Shabbir J, Britton DC. Stoma complications: a literature overview. Colorectal Dis 2010:12:958-64.

56 Persson E, Berndtsson I, Carlsson E, et al. Stoma-related complications and stoma size - a 2-year follow up. Colorectal Dis 2010;12:971-6.

57 Cottam J, Richards K, Hasted A, et al. Results of a nationwide prospective audit of stoma complications within 3 weeks of surgery. Colorectal Dis 2007;9:834-8.

58 Koivusalo A, Pakarinen MP, Rintala RJ. Surgical complications in relation to functional outcomes after ileoanal anastomosis in pediatric patients with ulcerative colitis. J Pediatr Surg 2007:42:290-5.

59 Simchuk EJ, Thirlby RC. Risk factors and true incidence of pouchitis in patients after ileal pouch-anal anastomoses. World J Surg 2000;24:851-6.

60 Pardi DS, Sandborn WJ. Systematic review: the management of pouchitis. Aliment Pharmacol Ther 2006;23:1087-96.

61 Akiyama S, Ollech J, Rai V, et al. 24 endoscopic and clinical characteristics of pouchitis involving the rectal cuff in patients with inflammatory bowel disease treated by proctocolectomy with ileal pouch-anal anastomosis. Gastroenterology 2020;158:S22-3.

62 Lee GC, Cavallaro PM, Savitt LR, et al. Bowel function after J-pouch may be more complex than previously appreciated: a comprehensive analysis to highlight existing knowledge gaps. Dis Colon Rectum 2020;63:207-16.

63 Ceriati E, De Peppo F, Rivosecchi M. Role of surgery in pediatric ulcerative colitis. Pediatr Surg Int 2013;29:1231-41. 
64 Gawad N, El Demellawy D, Wayne C, et al. Histologic inflammatory activity of the rectal margin as a predictor of postoperative complication in ileoanal anastomosis ( $\mathrm{J}$-pouch) procedure in children with refractory ulcerative colitis. J Pediatr Surg 2016;51:783-5.

65 Tan K-K, Ravindran P, Young CJ, et al. The extent of inflammation is a predictor for pouch-related complications in ileal pouches in patients with ulcerative or indeterminate colitis. Colorectal Dis 2014;16:620-5.

66 Drews JD, Onwuka EA, Fisher JG, et al. Complications after proctocolectomy and ileal pouch-anal anastomosis in pediatric patients: a systematic review. J Pediatr Surg 2019;54:1331-9.

67 Ateș U, Ergün E, Göllü G, et al. Laparoscopic proctocolectomy with ileal j-pouch anal anastomosis in children. Turk J Gastroenterol 2017;28:384-7.
68 Grobler SP, Hosie KB, Keighley MR. Randomized trial of loop ileostomy in restorative proctocolectomy. Br J Surg 1992;79:903-6.

69 de Montbrun SL, Johnson PM. Proximal diversion at the time of ileal pouch-anal anastomosis for ulcerative colitis: current practices of North American colorectal surgeons. Dis Colon Rectum 2009;52:1178-83.

70 Remzi FH, Lavryk OA, Ashburn JH, et al. Restorative proctocolectomy: an example of how surgery evolves in response to paradigm shifts in care. Colorectal Dis 2017;19:1003-12.

71 Gunnarsson U, Karlbom U, Docker M, et al. Proctocolectomy and pelvic pouch--is a diverting stoma dangerous for the patient? Colorectal Dis 2004;6:23-7. 